\title{
THE EFFECT OF COOPERATIVE INTEGRATED READING AND COMPOSITION (CIRC) LEARNING MODEL TO IMPROVE LEARNING OUTCOME OF INDONESIAN LANGUAGE IN DETERMINING SENTENCE OF ADVICE FOR GRADE 3 STUDENTS AT SD NEGERI 148 PEKANBARU
}

\author{
Ayu Nurzayyana ${ }^{1}$, Indah Putri Danyati², Zeti Akmalia ${ }^{3}$ \\ 1,2,3 Universitas Riau, Pekanbaru, Indonesia \\ Indahdanyati322@gmail.com, ${ }^{2} \underline{\text { Ayunurzayyana090@gmail.com }}, \underline{3 \text { Zetiakmalia13@gmail.com }}$
}

\begin{abstract}
This research was conducted at SDN 148 Pekanbaru. The subjects of this study were 29 grade 3 students consisting of 17 male students and 12 female students. This research aims to improve the learning outcomes of Indonesian students by applying the Cooperative Integ rated Reading and Composition (CIRC) learning model. The method used in this research was experiment. This research was conducted for 3 days, where the first day gave a pretest to students, the second day provided learning, and the third day was posttest. The results of the study were seen from the students pretest and posttest. On the results of the pretest of 29 students, there were 13 students who completed and 16 other students who did not complete with an average of 68.03. Then in the posttest, the number of students who have completed has increased by 26 people while students who have not completed were 3 people so that an average of 80.62 was obtained which was relatively high. The results of $t$-test with $t_{\text {count }}=10.17$ and $t_{\text {table }}=2.048$, which can be concluded that $t_{\text {count }}>t_{\text {table, }}$, then $H_{o}$ is rejected and $H_{a}$ is accepted, meaning that there were differences and increases in student learning outcomes at SD Negeri 148 Pekanbaru between before and after the implementation of the Cooperative Integrated Reading and Composition (CIRC) learning model.
\end{abstract}

Keywords: CIRC learning model, Indonesian learning outcomes

PENGARUH MODEL PEMBELAJARAN COOPERATIVE INTEGRATED READING AND COMPOSITION (CIRC) UNTUK MENINGKATKAN HASIL BELAJAR BAHASA INDONESIA DALAM MENENTUKAN KALIMAT SARAN SISWA KELAS III SD NEGERI 148 PEKANBARU

\begin{abstract}
ABSTRAK
Penelitian ini dilaksanakan di SDN 148 Pekanbaru. Subjek dari penelitian ini adalah siswa kelas 3 yang berjumlah 29 orang dimana terdiri dari 17 siswa laki-laki dan 12 siswa perempuan. Penilitian ini bertujuan untuk mengetahui perbedaan hasil belajar bahasa Indonesia siswa sebelum dan setelah diterapkan model pembelajaran Cooperative Integrated Reading and Composition (CIRC). Metode yang digunakan dalam penelitian ini yaitu eksperimen. Penelitian ini dilaksanakan selama 3 hari, dimana hari pertama memberikan pretest kepada siswa, hari kedua memberikan pembelajaran, dan hari ketiga adalah posttest. Hasil penelitian dilihat dari pretest dan posttest siswa. Pada hasil pretest dari 29 siswa, terdapat 13 siswa yang tuntas dan 16 siswa lainnya belum tuntas dengan rata-rata yaitu 68.03. Kemudian Pada posttest jumlah siswa yang tuntas sudah meningkat yaitu 26 orang sedangkan siswa yang belum tuntas yaitu 3 orang sehingga didapat rata-rata 80.62 yang tergolong tinggi. Hasil Uji-t dengan $t_{\text {hitung }}=$ 10.17 dan $t_{\text {tabel }}=2.048$, dapat disimpulkan bahwa $t_{\text {hitung }}>t_{\text {tabel}}$, maka $\mathrm{H}_{\mathrm{o}}$ ditolak dan $\mathrm{H}_{\mathrm{a}}$ diterima artinya terdapat perbedaan dan peningkatan dari hasil belajar siswa SD Negeri 148 Pekanbaru antara sebelum dan sesudah diterapkannya model pembelajaran Cooperative Integrated Reading and Composition (CIRC).
\end{abstract}

Kata Kunci: model pembelajaran CIRC, hasil belajar bahasa Indonesia

\begin{tabular}{|c|c|c|}
\hline Submitted & Accepted & Published \\
\hline 25 Februari 2020 & 13 Mei 2020 & 22 Juli 2020 \\
\hline
\end{tabular}

\begin{tabular}{|l|c|r|}
\hline Citation & $:$ & $\begin{array}{r}\text { Nurzayyana, A., Danyati, I.P., \& Akmalia, Z. (2020). The Effect of Cooperative Integrated Reading and Composition } \\
\text { (CIRC) Learning Model to Improve Learning Outcome of Indonesian Language in Determining Sentence of } \\
\text { Advice for Grade 3 Students at SD Negeri 148 Pekanbaru. Jurnal PAJAR (Pendidikan dan Pengajaran), 4(4), } \\
671-679 . \text { DOI : http://dx.doi.org/10.33578/pjr.v4i2.8012. }\end{array}$ \\
\hline
\end{tabular}




\section{PENDAHULUAN}

Saat ini pendidikan merupakan hal yang sangat penting bagi kehidupan manusia. Pendidikan merupakan sebagai bentuk usaha sadar, dimana proses pendidikan dilakukan secara berencana dalam mewujudkan suasana dan proses pembelajaran agar peserta didik (siswa) dapat seacara aktif mengembangkan potensi yang ada dalam dirinya agar mendapatkan kekuatan spiritual, agama, pengendalian diri, akhlak mulia, kecerdasan serta keterampilan yang sangat diperlukan oleh peserta didik dalam masyarakat dan merupakan tuntunan perkembangan zaman (Syarif, 2013)

Guru memiliki peranan yang sangat penting terutama dalam pembentukan watak bangsa dan karakter siswa melalui pengembangan kepribadian dan nilai-nilai yang diinginkan. Adapun tanggung jawab guru yaitu : (1) Bertugas sebagai pengajar; (2) Bertugas sebagai pembimbing; (3) Bertugas sebagai administator kelas; (4) Bertugas sebagai pengembang kurikulum; (5) Bertugas untuk mengembangkan profesi; (7) Bertugas untuk membina hubungan dengan masyarakat. (Syaefudin, 2010)

Bahasa Indonesia memiliki peran yang sangat penting untuk meningkatkan pendidikan baik bagi seorangan, masyarakat, bangsa dan bernegara. Bahasa Indonesia adalah salah satu mata pelajaran resmi di Negara ini. Dalam proses pembelajarannya, para peserta didik harus mencapai kriteria ketuntasan minimum (KKM). Yang mana KKM tersebut menjadi tolak ukur ketuntasan atau keberhasilan siswa dalam menerima pembelajaran di sekolah.

Pembelajaran bahasa Indonesia memiliki 4 cakupan yang sangat penting, seperti membaca, menulis, menyimak, berbicara. Pembelajaran bahasa Indonesia sangat memegang peranan yang penting dalam kehidupan kita sehari-hari (Solchan, 2011). Para peserta didik (siswa) tentunya harus bisa menguasai 4 keterampilan tersebut, dimana setiap siswa saat menempuh jenjang kelas rendah SD, siswa harus dapat menulis dan membaca. Pada kegiatan ini siswa dimulai dengan mengenal huruf, menyusun kata, membentuk kalimat, paragraph dan menulis karangan dengan baik. Kemudian pada saat siswa kelas tinggi di SD, siswa harus mampu menyimak dan berbicara.

Untuk mencapai ketuntasan siswa dalam pembelajaran bahasa Indonesia, maka dibutuhkan peran guru dalam proses belajar mengajar dengan menggunakan model, metode, dan strategi yang sesuai dengan pembelajaran. Namun, pada saat sekarang ini banyak sekali guru-guru di sekolah dasar menggunakan model atau metode pembelajaran yang tidak sesuai dengan pembelajaran bahkan model pembelajaran tersebut cenderung kaku. Dalam menyampaikan pembelajaran, guru lebih cenderung menggunakan metode ceramah, sehingga membuat siswa menjadi mudah bosan dan tujuan pembelajaran tidak tersampaikan dengan baik. Teladaningsih dkk (2019) mengatakan bahwa penyebab dari rendahnya proses hasil belajar siswa disebabkan karena guru yang masih mendominasi dalam kegiatan pembelajaran, guru hanya menggunakan papan tulis serta cenderung memakai metode ceramah dalam hal ini guru tidak menggunakan media dan model yang relevan dalam pembelajaran.

Dari permasalahan di atas, maka peneliti menggunakan metode eksperimen untuk mengetahui sejauh mana pemahaman siswa kelas 3 SD Negeri 148 Pekanbaru pembelajaran bahasa Indonesia tentang kalimat saran. Dalam penelitian ini, para peneliti juga menggunakan model pembelajaran kooperatif CIRC (Cooperative Integrated Reading and Composition). Model pembelajaran kooperatif CIRC yaitu model pembelajaran yang melibatkan kerjasama siswa dalam suatu kelompok untuk menyelesaikan suatu tugas atau permasalahan. Dalam model kooperatif CIRC, siswa diarahkan untuk memberikan pemahaman kepada temannya yang belum paham, kemudian siswa dituntut untuk aktif dalam menyampaikan hasil diskusinya kepada temantemannya, dan mampu menjawab sanggahan yang diberikan oleh teman-temannya. 


\section{KAJIAN TEORETIS}

Metode pembelajaran kooperatif merupakan metode atau strategi pembelajaran gotong royong yang konsepnya hampir tidak jauh berbeda dengan metode pembelajaran berkelompok. Meski pembelajaran kooperatif berbeda dengan pembelajaran berkelompok, akan tetapi ada beberapa unsur yang membedakannya antara pembelajaran kooperatif dan berkelompok (Saputra \& Ridyanto, 2005). Pembelajaran kooperatif guru lebih bisa mengelolah kelas dengan lebih efektif. Proses pembelajaran kooperatif ini siswa tidak harus menerima pembelajaran yang diberikan oleh guru akan tetapi pembelajaran kooperatif ini juga bisa didapatkan melalui teman-teman secara berkelompok. Sedangkan metode pembelajaran berkelompok adalah metode yang mana memfokuskan hanya kepada kerja perkelompok terhadap siswa akan tetapi guru sama sekali tidak memberi bimbingan atau penjelasan, jadi siswa ditekankan untuk mengerjakan pembelajaran dengan teman kelompoknya.

Menurut Jarolimek dan Parker (Isjoni, 2010) mengatakan keunggulan dari pembelajaran kooperatif: 1) Saling ketergantungan yang positif; 2) Adanya pengakuan dalam merespon perbedaan individu; 3) Siswa dilibatkan dalam perencanaan dan pengelolaan kelas; 4) Suasana kelas yang rileks dan menyenangkan; 5) Terjalinnya hubungan yang hangat dan bersahabat antara siswa dengan guru; 6) Memiliki banyak kesempatan untuk mengekspresikan pengalaman emosi yang menyenangkan.

Berdasarkan pengertian di atas keunggulan dalam pembelajaran kooperatif yaitu mencakup sistem bergotong royong yang mana setiap siswa melakukan pembelajaran dengan berkelompok, akan tetapi antara guru dan siswa tetap menjalin hubungan timbal balik agar tercapainya suasana yang efektif.

Pembelajaran yang menggunakan model CIRC membawa konsep pemahaman inovatif sehingga dapat mengoptimalkan hasil belajar bahasa Indonesia (Abidin, 2012). Sebagai guru pasti ingin meningkatkan keterampilan berbahasa, kemampuan berpikir, kemampuan bernalar, serta memperluas wawasan peserta didik (siswanya), untuk itu hal yang harus dilakukan yaitu menerapkan model pembelajaran kooperatif CIRC (Cooperative Integrated Reading and Compostion). Dalam sebuah pembelajaran jika diterapkan model pembelajaran kooperatif CIRC siswa dapat memperluas wawasan, mempunyai suasana baru dalam belajar sehingga siswa tidak bosan dan siswa akan mendapatkan pembelajaran yang menarik (tidak monoton).

Model CIRC adalah komposisi terpadu membaca dan menulis secara kooperatif atau kelompok (Suyatno, 2009). Dengan menggunakan model CIRC ini membuat siswa termotivasi dalam belajarnya , karena salah satu ciri dari model pembelajaran CIRC ini adalah berkelompok untuk bekerja. Sehingga siswa mendapatkan bantuan dari teman-teman sebayanya atau teman sekelompoknya, jadi siswa tidak hanya berpatokan pengetahuan dari guru saja, kemudian siswa lebih termotivasi dengan dibentuknya kelompok untuk bekerja ini yang bertujuan untuk meningkatkan cara berpikir siswa, belajar yang cepat dan akurat sehingga siswa dapat menuntaskan pembelajaran dengan cepat dan lebih paham materi yang diajarkan secara keseluruhan.

Adapun beberapa keunggulan penerapan pembelajaran kooperatif CIRC antara lain (Suyitno, 2005): 1) Model CIRC sangat tepat untuk meningkatkan keterampilan siswa dalam menemukan kalimat utama dalam sebuah paragraph; 2) Dominasi guru dalam pembelajaran berkurang; 3) Siswa termotivasi pada hasil secara teliti karena bekerja dalam berkelompok; 4) Membantu siswa yang kurang pintar dalam berkelompok; 5) Meningkatkan hasil belajar bahasa Indonesia khususnya dalam menemukan kalimat utama dalam suatu paragraph.

Pembelajaran CIRC ini adalah pembelajaran yang keluar atau yang terkonsep secara otomatis dari bahasa siswa sendiri, sehingga berdiskusi dengan kelompok siswa dapat sangat mudah memahami pelajaran atau materi yang susah atau sulit dipahami. Kegiatan berdiskusi tersebut yang membuktikan bahwa siswa telah berhasil dalam memenuhi sebuah konsep model 
pembelajaran kooperatif CIRC. Dalam berdiskusi jika terdapat salah satu siswa yang kurang mampu dalam menguasai materi atau lemahnya cara berfikir maka siswa yang lebih mengerti atau yang lebih menguasai materi memberi tahu atau menjelaskan secara detail tentang materi yang sulit tersebut, sehingga didalam berkelompok ini semua siswa dapat mengeti materi secara detail tanpa harus malu. Karena dalam satu kelompok hanya ada teman-teman kelasnya saja.

Terdapat langkah-langkah dalam proses melaksanakan pembelajaran yang menggunakan CIRC , diantaranya yaitu (Afandi Muhammad dkk, 2013): 1) Guru membentuk kelompok yang anggotanya empat atau lima orang secara heterogen (berbeda jenis kelamin, latar belakang status social, kemampuan akademik dll);2) Guru memberikan wacana sesuai dengan topic atau materi yang diajarkan; 3) Siswa bekerjasama saling membacakan dan menemukan ide pokok dan memberikan tanggapan terhadap wacana dan tulisan pada selembar kertas; 4) Perhatian siswa terhadap pelajaran guru, aktifitas siswa terhadap situasi kelompok, membantu teman yang kesulitan, kemampuan siswa bertanya materi yang belum jelas, kemampuan siswa mengemukakan pendapat, siswa mampu memberi sanggahan dan tanggapan, keberanian siswa mempresentasikan hasil diskusinya, membuat kesimpulan sendiri, kemampuan siswa dalam mengerjakan soal; 5) Guru membuat kesimpulan Bersama; 6) Pada akhir pembelajaran guru memberikan kuis atau soal untuk mengetahui tingkat kepahaman siswa pada materi yang telah diajarkan.

Pembelajaran kooperatif ini memiliki tujuan pembelajaran yang mana diantaranya yaitu (Isjoni: 2007): 1) Hasil belajar akademik, walapun

\section{METODE PENELITIAN}

Metode yang digunakan dalam penelitian ini adalah eksperimen (pre eksperimen) dengan bentuk penelitian one grup pretest posttest design. Sampel dari penelitian ini adalah siswa kelas $3 \mathrm{~A}$ SD Negeri 148 Pekanbaru semester ganjil dengan jumlah siswa 29 yang terdiri dari 17 siswa laki-laki dan 12 siswi perempuan. Penelitian dilakukan selama 3 hari yaitu pada tanggal 11 November, 15 di dalam pembelajaran kooperatif ini sudah banyak mencakup beberapa tujuan sosial, akan tetapi di dalam pembelajarn ini prestasi juga harus diperbaiki ataupun berbagai tugas akademis yang lain. Para ahli mennyatakan bahwa pembelajaran kooperatif ini unggul di dalam pembelajaran guna untuk membantu pembelajaran siswa dalam memahamai konsep belajar; 2) Penerimaan terhadap perbedaan individu, maksudnya adalah di dalam pembelajaran kooperatif ini setiap siswa atau setiap individu harus bisa menerima setiap temannya atau setiap kelompoknya walapun di dalam suatu kelompok itu tidak dalam satu suku, budaya, ras, maupun keberadaan social serta perbedaan perkembangan dan cara berpikirnya, jadi di dalam pembelajaran ini siswa ditekankan untuk menerima atau menghargai satu dengan yang lainnya; 3) Pengembangan keterampilan social, di dalam pembelajaran kooperatif ini siswa juga ditekankan untuk terampil bekerja sama atau berkelompok, sehingga siswa tidak lagi kebingungan jika terdapat konsep yang sulit dipahami.

Dalam mencakup pengertian kooperatif dari Isjoni, maka tujuan dari pembelajaran kooperatif ini yaitu pembelajaran yang mana selalu mengutamakan kerjasama dalam berkelompok tanpa membedakan suku, budaya, ras, maupun keberadaan sosial serta perbedaan perkembangan dan cara berpikir, jadi setiap siswa benar-benar ditekankan untuk dapat saling memahami dan mengerti dari setiap perbedaan-perbedaan yang ada dan didalam pembelajaran ini siswa tidak lagi kebingungan apabila di dalam pembelajaran terdapat konsep yang sulit dipahami.

November dan 18 November tahun 2019. Teknik pengumpulan data pada penelitian ini adalah dengan memberikan tes tertulis kepada siswa dan siswi. Tes yang diberikan memiliki tujuan yaitu untuk mengetahui hasil belajar siswa. Pemberian tes ini dilakukan di awal pertemuan sebelum diberikannya pembelajaran dengan model CIRC dan diakhir pertemuan setelah diberikan 
pembelajaran dengan menerapkan model CIRC. Teknik analisis data dalam penelitian yaitu dengan mengumpulkan data dari nilai pretest dan posttest yang kemudian diolah menggunakan rumus statistik sederhana serta hasil ketuntasan belajar siswa.

Pada penelitian ini, sebelum diberikan perlakuan, kelas eksperimen terlebih dahulu diberikan pretest (tes awal), kemudian setelah diberikan pretest barulah siswa diberikan perlakuan atau pembelajaran dengan menggunakan model Cooperative Integrated Reading and Composition (CIRC). Setelah diberikan pembelajaran, siswa diberikan posttest (tes akhir) Berikut di bawah ini adalah desain penelitian:

Tabel 1. Desain Penelitian

\begin{tabular}{|c|c|c|}
\hline pretest & Treatment & Posttest \\
\hline $\mathbf{O}_{1}$ & $\mathbf{X}$ & $\mathbf{O}_{2}$ \\
\hline
\end{tabular}

Keterangan:

$\mathrm{O}_{1}$ : Pretest yang merupakan test awal sebelum diberikan perlakuan
$\mathrm{X}$ : Perlakuan/pembelajaran yang menggunkan model CIRC

$\mathrm{O}_{2}$ : Posttest yang merupakan test akhir yang diberikan sesudah perlakuan/pembelajaran.

\section{HASIL DAN PEMBAHASAN}

Hari selasa, 11 November 2019 merupakan hari pertama melakukan penelitian di SD Negeri 148 Pekanbaru. Pada hari selasa, peneliti memberikan pretest kepada siswa dan siswi kelas 3 SD. Soal pretest yang diberikan berjumlah 5 buah soal yaitu dalam bentuk soal essay, pretest ini bertujuan untuk mengetahui sejauh mana pemahaman siswa terhadap materi pembelajaran yang akan diajarkan kepada mereka. Setelah diberikan pretest ternyata terdapat 16 siswa yang belum memahami pembelajaran dan 13 siswa lainnya sudah mulai memahami materi pembelajaran. Pada hari Jum'at, 15 November 2019, peneliti mengajarkan siswa dan siswa di SD Negeri 148 Pekanbaru mengenai pembelajar tema 4 sub tema 1 pembelajaran ke 5 yang mana membahas tentang kalimat saran. Dalam mengajar, peneliti menggunakan model pembelajaran Cooperative Integrated Reading and Composition (CIRC). Dalam proses belajar mengajar menggunakan model tersebut, peneliti membagi siswa dan siswi menjadi 5 kelompok. Kemudian peneliti menggunakan media gambar yang ditempelkan di depan kelas. Media gambar tersebut, peneliti meminta masing-masing kelompok untuk mengamati gambar tersebut dan mencari penyelesaian dari masalah tersebut. Setelah masing-masing kelompok selesai mengamati, peneliti meminta masing-masing kelompok untuk menyampaikan hasil diskusinya di depan kelas. Dari model pembelajaran Cooperative Integrated Reading and Composition (CIRC) siswa dapat lebih aktif, melatih kerjasama dalam kelompok serta juga melatih percaya diri siswa siswi tersebut. Pada hari senin, 18 November 2019, merupakan hari ketiga untuk melakukan penelitian. Pada hari ini, peneliti memberikan soal Posttest kepada siswa siswi. Soal posttest ini berjumlah 5 buah soal dalam bentuk essay dimana harus dikerjakan oleh masingmasing individu. Setelah 3 hari melakukan penelitian, maka peneliti mulai menganalisis hasil dari pretest dan posttest yang telah diberikan kepada siswa siswa di SD Negeri 148 Pekanbaru.

Hasil analisis data dari pretest dan posttest menghasilkan rata-rata, standar deviasi, dan varians pada kelas eksperimen yang terdapat pada tabel di bawah ini. 
Tabel 2. Hasil Belajar Bahasa Indonesia (pretest dan posttest)

\begin{tabular}{lcccccc}
\hline Data & $\begin{array}{c}\text { Jumlah } \\
\text { Siswa }(\mathbf{n})\end{array}$ & Rerata $(\overline{\boldsymbol{x}})$ & $\begin{array}{c}\text { Standar } \\
\text { Deviasi }(\mathbf{s})\end{array}$ & Varians $\left(\mathbf{s}^{\mathbf{2}}\right)$ & Nilai Min & Nilai Max \\
\hline Pretest & 29 & 68.03 & 12.42 & 4.98 & 45 & 85 \\
Posttest & 29 & 80.62 & 8.39 & 3.21 & 60 & 100 \\
\hline
\end{tabular}

Dari tabel diatas, terdapat rata-rata dari hasil belajar pretest yaitu 68.03 yang termsuk kurang sedangkan rata-rata dari hasil sesudah belajar (posttest) yaitu 80.62 yang termasuk tinggi.

\section{Uji-t dari pretest dan posttest}

Untuk mengetahui perbandingan dari nilai pretest dan posttest dari hasil belajar bahasa Indonesia dengan menggunakan model CIRC (Cooperative Integrated Reading and Composition), maka dilakukan dengan Uji-t, yang terdapat pada tabel di bawah ini.

Table 3. Tabel Uji-t Nilai Pretest dan Posttest

\begin{tabular}{cccccccc}
\hline $\mathbf{D}$ & $\mathbf{d}^{\mathbf{2}}$ & $\mathbf{d k}(\mathbf{n}-\mathbf{1})$ & $\mathbf{t}_{\text {hitung }}$ & $\boldsymbol{\alpha}$ & $\mathbf{t}_{\text {tabel }}$ & keterangan & Kesimpulan \\
\hline 12.76 & 6.000 & 28 & 10.17 & 0.05 & 2.048 & Tolak $\mathrm{H}_{\mathrm{o}}$ & signifikan \\
\hline
\end{tabular}

Dari tabel di atas, dengan membandingkan $\mathrm{t}_{\text {hitung }}$ dengan $\mathrm{t}_{\text {tabel }}$ di mana $\alpha=0.05 \mathrm{dan} \mathrm{dk}=28$, jika disesuaikan dengan tabel distribusi $\mathrm{t}$ dan $\mathrm{dk}=$ 28, maka $t_{\text {tabel }}=2.048$. Karena $t_{\text {hitung }}$ di luar rentang tabel yaitu $-2.048<\mathrm{t}_{\text {hitung }}<2.048$, maka $\mathrm{H}_{\mathrm{o}}$ ditolak, dan dapat disimpulkan pada taraf kepercayaan $95 \%$ model pembelajaran CIRC meningkatkan hasil belajar siswa.

\section{Hasil Belajar Siswa}

Tabel 4. Ketuntasan Hasil Belajar

\begin{tabular}{cccccc}
\hline \multirow{2}{*}{ Tahap } & \multirow{2}{*}{ Jumlah siswa } & \multicolumn{2}{c}{$\begin{array}{c}\text { Ketuntasan hasil belajar } \\
\text { Individual }\end{array}$} & Rata-rata & keterangan \\
& & Tuntas & Tidak Tuntas & & \\
\hline Pretest & 29 & $13(44.83 \%)$ & $16(55.17 \%)$ & 68.03 & Tidak Tuntas \\
posttest & 29 & $26(89.66 \%)$ & $3(10.34 \%)$ & 80.62 & Tuntas \\
\hline
\end{tabular}

Berdasarkan data dari tabel 3 di atas, pada hasil pretest terdapat 13 siswa yang tuntas dengan persentase yaitu $44.83 \%$ dan siswa yang belum tuntas sebanyak 16 siswa dengan persentase 55, $17 \%$ dengan rata-rata 68.03 sehingga menghasilkan keterangan tidak tuntas. Namun setelah diterapkannya model pembelajaran CIRC
(Cooperative Integrated Reading and Composition), hasil belajar siswa dilihat dari data posttest mengalami peningkatan, yang mana terdapat 26 siswa yang tuntas dengan persentase $89.66 \%$ dan siswa yang tidak tuntas yaitu 3 orang dengan persentase $10.34 \%$, sehingga di dapat ratarata yaitu 80.62 dengan keterangan tuntas. 


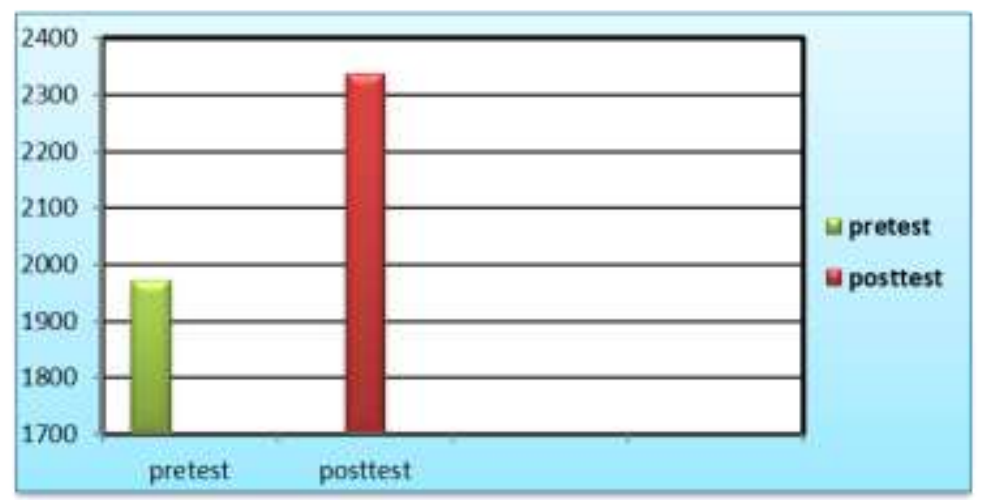

Gambar 1. Grafik Data dari Hasil Pretest Dan Posttest

Dari grafik diatas menunjukkan bahwasanya terdapat terdapat perbedaan dari hasil pretest dan posttest siswa. Di mana hasil pretest siswa yaitu sebesar 1.973 dan hasil posttest 2.338.

\section{Pembahasan}

Saat memberikan pembelajaran kepada siswa, ada beberapa hal yang harus diperhatikan yaitu, model pembelajaran, media pembelajaran, pendekatan dalam pembelajaran dan lain-lain. Menurut Orthied (2013), seorang guru memiliki tantangan terbesar yaitu memilih dan menggunakan strategi serta model pembelajaran yang harus di sesuaikan dengann materi yang akan diajarkan. Model pembelajaran CIRC dapat meningkatkan pemahaman dan hasil belajar siswa. Hal ini dapat dilihat dari hasil penelitian yang telah dilaksanakan pada siswa siswi kelas 3 A di SD Negeri 148 Pekanbaru dengan menggunakan model CIRC. Penggunaan model pembelajaran CIRC dapat meningkatkan hasil belajar siswa dan siswi kelas 3 A di SD Negeri 148 Pekanbaru.

Dari analisa data di atas, terdapat hasil yang menyatakan bahwa model pembelajaran CIRC (Cooperative Integrated Reading and Composition) memberikan pengaruh terhadap hasil belajar siswa dalam membuat dan menentukan kalimat saran.

Sebelum masuk ke pembelajaran, peneliti memberikan tes awal terlebih dahulu, dari tes awal (pretest) yang dilakukan didapat rata-rata 68.03. Setelah itu, siswa diberikan perlakuan atau pembelajaran tentang kalimat saran dengan
Hal ini menunjukkan bahwasanya model pembelajaran CIRC dapat memberikan pengaruh terhadap hasil belajar siswa.

menggunakan model pembelajaran CIRC (Cooperative Integrated Reading and Composition). Setelah diberikan perlakuan, maka siswa diberikan tes akhir (posttest). Dari hasil posttest didapat rata-rata yaitu 80.62. dari rata-rata pretest dan posttest dapat dilihat adanya peningkatan hasil belajar siswa dan siswa dengan menggunakan model CIRC.

Dari analisis data pretest dan posttest dengan menggunakan uji $\mathrm{t}$ terdapat perbandingan rata-rata siswa sebelum dan sesudah diberi perlakuan, dari analisis ini menunjukkan adanya peningkatan yang signifikan terhadap hasil belajar siswa dengan menggunakan model pembelajaran CIRC. Saat dilakukan uji-t terdapat keterangan bahwasanya $\mathrm{H}_{\mathrm{o}}$ ditolak, maka jika $\mathrm{H}_{\mathrm{o}}$ ditolak maka $\mathrm{H}_{\mathrm{a}}$ diterima artinya $\mathrm{H}_{\mathrm{a}}=$ adanya perbedaan hasil belajar siswa sebelum dan sesudah diberi perlakuan.

Kemudian dilihat dari analisis hasil belajar siswa, pada pretest terdapat 16 siswa yang belum tuntas dengan persentase $55.17 \%$ dan 13 siswa sudah tuntas dengan persentase yaitu 44.83\%, maka di dapat keterangan bahwa hasil pretest siswa dan siswi belum tuntas. Setelah diberikan perlakuan dengan model CIRC di dapat hasil posttest yaitu terdapat 26 siswa yang tuntas 
dengan persentase yang sangat meningkat yaitu $89.66 \%$ dan 3 orang yang belum tuntas dengan persentase 10.34, maka dari hasil tersebut di dapat keterangan bahwasanya hasil belajar siswa tuntas setalah diberikan pembelajaran dengan

\section{SIMPULAN DAN REKOMENDASI}

Berdasarkan hasil dan pembahasan yang telah dikemukakan dapat ditarik kesimpulan bahwa terdapat perbedaan dari hasil belajar siswa dengan menggunakan model pembelajaran CIRC (Cooperative Integrated Reading and Composition). Dimana nilai rata-rata dari hasil pretest 68.03 dan pada post test 80.62 . kemudian setelah dilakukan uji $\mathrm{t}$ terdapat perubahan signifikan yang mana dengan membandingkan $\mathrm{t}_{\text {hitung }}$ dengan $\mathrm{t}_{\text {tabel }}$ di mana $\alpha=0.05 \mathrm{dan} \mathrm{dk}=28$, jika disesuaikan dengan tabel distribusi $\mathrm{t}$ dan $\mathrm{dk}=$ 28 , maka $t_{\text {tabel }}=2.048$. Karena thitung diluar rentang $\mathrm{t}_{\text {tabel }}$ yaitu $-2.048<\mathrm{t}_{\text {hitung }}<2.048$, maka $\mathrm{H}_{\mathrm{o}}$ ditolak, dan dapat disimpulkan pada taraf kepercayaan $95 \%$ model pembelajaran CIRC (Cooperative Integrated Reading and Composition) meningkatkan hasil belajar siswa.

Dari data grafik juga menunjukkan adanya peningkatan yang signifikan dari hasil pretest dan

\section{DAFTAR PUSTAKA}

Abidin, Y. (2012). Pembelajaran Membaca Berbasis Pendidikan Karakter. Bandung: PT Refika Aditama.

Afandi, M. Dkk. (2013). Model dan Metode Pembelajaran di Sekolah. Semarang : UNISSULA PRESS.

Hidayat, S. (2013). Teori dan Prinsip Pendidikan. Jakarta: PT Pustaka Mandiri.

Isjoni. (2007). Cooperative Learning mengembangkan Kemampuan Belajar Berkelompok. Bandung : Alfabeta.

Isjoni. (2010). Cooperative Learning Efektivitas Pembelajaran Kelompok. Bandung: Alfabeta.

Saputra,Y.M dan Ridyanto. (2005). Pembelajaran Kooperatif untuk Meningkatkan Keterampilan Anak TK. Jakarta: Depdikbud. menggunakan model CIRC. Hal ini sesuai dengan penelitian Yuwanda dkk (2019), bahwa model CIRC berpengaruh positif terhadap kemampuan siswa dalam menentukan kalimat saran.

posttest, hal ini menunjukkan bahwa setelah diberikan perlakuan dengan model CIRC hasil posttest menjadi meningkat dibandingkan dengan hasil pretest. Sehingga proses belajar mengajar dengan menggunakan model pembelajaran CIRC dapat meningkatkan hasil belajar siswa dan siswi sesuai dengan yang diharapkan oleh guru.

Berdasarkan hasil penelitian diatas dapat direkomendasikan hal-hal sebagai berikut: 1) Untuk guru yang akan menerapkan model pembelajaran CIRC, hendakknya guru memahami dengan baik langkah-langkah CIRC agar tujuan pembelajaran tercapai secara maksimal; 2) Selain itu guru dituntut untuk mengetahui permasalahanpermasalahan yang dihadapi oleh siswa dan siswinya; 3) Untuk peneliti berikutnya dapat dijadikan sebagai referensi untuk melakukan penelitian yang berhubungan dengan model pembelajaran CIRC.

Saud, U. (2010). Pengembangan Profesi Guru. Bandung : Alfabeta.

Solchan, dkk. (2011). Pendidikan Bahasa Indonesia di SD. Jakarta: Universitas Terbuka.

Suyatno. (2009). Menjelajah Pembelajaran Inovatif. Surabaya: Masmedia Buana Pustaka.

Suyitno, A. (2005). Mengadopsi Pembelajaran CIRC Dalam meningkatkan keterampilan siswa Menyelesaikan Soal Cerita. Surabaya : Masmedia Buana Pustaka.

Ortlieb, E. (2013). Using Anticipatory Reading Guides to Improve Elementary Students'Comprehension. Internasional Journal of Instruction, 6(2), 145-162.

Santika, M.Y., Kurniaman, O., \& Antosa, Z. (2019). Pengaruh Model Pembelajaran 
Jurnal PAJAR (Pendidikan dan Pengajaran)

Volume 4 Nomor 4 Juli 2020 | ISSN Cetak : 2580 - 8435 | ISSN Online : 2614 - 1337

DOI : http://dx.doi.org/10.33578/pjr.v4i2.8012

Cooperative Integrated Learning and Composition (CIRC) Terhadap Kemampuan Menentukan Ide Pokok Paragraf Siswa Kelas V SD Negeri 003 Pulau Kopung Kecamatan Sentajo Raya Kabupaten Kuantan Singingi. Jurnal PAJAR (Pendidikan dan Pengajaran), 3(2), 306-312.
Teladaningsih, O., Mawardi., \& Hulian, I. (2019). Implementasi Model Pembelajaran Teams Games Tournment Meningkatkan Keterampilan Kolaboratif peserta didik Kelas 4 SD. Pendas: Juranl Ilmiah Pendidikan Dasar, 4(1), 17-30. 